\title{
Total Intra-Venous Anesthesia for Parathyroid Adenoma in a Child
}

\begin{abstract}
Bhavna Gupta, ${ }^{*}$ Neelam Prasad Govil, Munisha Agarwal, Vandana Saith
Department of Anesthesia and Critical Care, Maulana Azad Medical College and Lok Nayak Hospital, New Delhi, India

ABSTRACT

Endocrine surgeries present a unique challenge to the attending surgeon and anesthesiologist and parathyroid adenoma is no exception. Parathyroid disorders are rare in children. Most striking disturbance in this disorder is the imbalance of calcium levels in body and main emphasis of management revolves around the same in perioperative period. We are reporting the anesthesia management for parathyroidectomy with total intra-venous anesthesia (TIVA).
\end{abstract}

Key words: TIVA; Parathyroid adenoma; Child.

Correspondence*: Bhavna Gupta, Department of Anesthesia and Critical Care, Maulana Azad Medical College and Lok Nayak Hospital, New Delhi, India

E-mail: bhavna.kakkar@gmail.com

(C) 2017, Gupta et al.

Submitted: 31-07-2017

Accepted: 10-10-2017

Conflict of Interest: None

Source of Support: Nil

This is an open-access article distributed under the terms of the Creative Commons Attribution License, which permits unrestricted use, distribution, and reproduction in any medium, provided the original work is properly cited.

\section{INTRODUCTION}

The incidence of primary hyperparathyroidism (PHPT) in pediatric age group is 1 per 200-300,000 and its prevalence is $2-5$ in 100,000 as compared to adult population $(1: 500-2000) \cdot[1,2]$ Precautionary measures have to be taken regarding the administration of volatile anesthetic agents and induction agents like thiopentone that can prolong the QTC interval.[3] Preoperative optimization is required to prevent perioperative complications. Short acting opioids such as fentanyl and propofol, due to rapid onset and recovery, have been used for such patients as combination under TIVA. TIVA has become increasingly popular and useful for parathyroidectomy.[4].

\section{CASE REPORT}

An 11-year-old female, weighing $25 \mathrm{~kg}$, underwent workup for multiple fractures. Biochemical investigations showed hemoglobin of $9.1 \mathrm{~g} \%$, platelet count $2.84 / \mathrm{micro}-$ liter, calcium $9.1 \mathrm{mg} / \mathrm{dl}$, ionized calcium $4.1 \mathrm{mmol} / /$, parathormone (PTH) $1225 \mathrm{pg} / \mathrm{ml}$, phosphate $1.2 \mathrm{meq} / \mathrm{l}$, alkaline phosphatase $1700 \mathrm{IU} / \mathrm{l}$, and albumin $2.9 \mathrm{mg} / \mathrm{dl}$.
Contrast enhanced CT scan of neck showed an oval lesion postero-inferior to right lobe of thyroid gland. Diffuse osteoporosis, and a lytic lesion in alveolar margin of right maxilla with bilateral clavicle fractures were also present. Non-contrast CT scan of brain revealed a $2 \mathrm{~mm}$ calcified granuloma in right parietal region with diffuse calvarial thickening in right parietal region. MIBI (99mTc-parathyroid-Methoxy-iso-butyl-iso-nitrile) scintigraphy revealed persistence of focal tracer activity in the lateral aspect of thyroid gland suggesting right parathyroid adenoma. She was evaluated for associated multiple endocrine neoplasia (MEN) syndrome by mutational studies, ultrasound abdomen and KUB (kidney-ureter-bladder) to rule out pancreatic involvement or nephrocalcinosis.

After syndromic association was ruled out, she was put on intra-venous fluids (40ml/hour), zoledronic acid and furosemide. Subsequently her calcium levels decreased to $8.5 \mathrm{mg} / \mathrm{dl}$. Patient was then scheduled for right parathyroidectomy under TIVA. Preoperative preparation included use of anxiolytics and aspiration prophylaxis. Morning serum electrolytes including calcium were in 
normal limits. Adequate hydration was provided via wide bore cannula and inj. dexmedetomidine infusion was started at $0.4-0.7$ micrograms/hour titrated to hemodynamic response. She was pre-oxygenated with $100 \%$ oxygen and induced with intravenous fentanyl $75 \mathrm{mi}-$ crograms, and propofol in titrated doses (total of $60 \mathrm{mg}$ ) and atracurium $15 \mathrm{mg}$.

Endotracheal intubation was done with flexometallic cuffed endotracheal tube sized 5.5 placed in neutral position. Superficial cervical plexus block was given on right side with $4 \mathrm{ml}$ of $0.25 \%$ bupivacaine to provide pain relief. Anesthesia was maintained on 0.5:0.5-O2: N2O under low flow anesthesia with infusion of dexmedetomidine at $4-14 \mathrm{microgram} / \mathrm{hour}$ and propofol at $2-4 \mathrm{ml} / \mathrm{hr}$. Atracurium was given according to neuromuscular monitoring. Patient was continuously monitored for heart rate and rhythm disturbances. End-tidal carbon dioxide, calcium levels (post induction, pre-extubation) were maintained in the normal range. Parathyroidectomy was done uneventfully. Procedure lasted for two hours. After completion of surgery, residual paralysis was reversed with neostigmine and glycopyrrolate in dose of 1.5 and $0.2 \mathrm{mg}$ respectively according to neuromuscular monitoring. During extubation, position of vocal cords was checked to assess the recurrent laryngeal nerve status. Postoperatively child was closely observed for symptoms of hypocalcemia and serum calcium levels were checked regularly. Her postoperative course was uneventful, and patient discharged home after one week.

\section{DISCUSSION}

Patients with parathyroid adenoma are prone to develop hypercalcemic crisis. This is managed with infusion of fluids, bisphosphonates, calcitonin, furosemide and steroids.[5] Regional anesthesia such as superficial and deep cervical plexus blockades, has been used for parathyroid surgery but such techniques can be extremely hazardous in the light of inadequate anesthesia and can cause numerous complications ranging from paresthesia to cardio-respiratory arrest.[6] Precautionary measures have to be taken during administration of anesthesia as thiopentone and volatile anesthetic agents prolong the QTc interval.[4]
TIVA is beneficial in as it avoids untoward side effects of volatile drugs on QT interval, provides adequate analgesia, maintains hemodynamics, prevents postoperative nausea and vomiting and ensure smooth recovery of the patient.[5] The most striking electrolyte disturbance during parathyroid surgery is the imbalance of calcium levels in the body. Patients may develop profound hypocalcemia immediately or in subsequent 24 hours after removal of parathyroid glands, therefore mandating the frequent assessment of calcium levels.[4] Hypercalcaemia may cause inadequate reversal due to unpredictable augmentation of non-depolarizing neuromuscular blockade, thus possibly leading to postoperative hypoxemia and respiratory obstruction. Dexmedetomidine, a type of alpha 2 agonist, is a desirable drug, as it not only allows for a smooth recovery, but also decreases the amount of intraoperative anesthetic and analgesic drugs during perioperative period.[5] Smooth extubation is desirable in awake state after establishing regular respiration with adequate tidal volume breaths to avoid any stress response and accidental hemorrhage from the operative site. TIVA was found to be an ideal anesthetic of choice in our case.

Authors' Contribution: All authors contributed equally in concept, literature review, and drafting of the manuscript and approved the final version of this manuscript.

\section{REFERENCES}

1. Roizen J, Levine MA. Primary hyperparathyroidism in children and adolescents. J Chinese Med Assoc. 2012;75:42534.

2. Alagaratnam S, Kurzawinski TR. Aetiology, diagnosis and surgical treatment of primary hyperparathyroidism in children: new trends. Horm Res Paediatr. 2015;16:1-11.

3. Wall RT. Stoelting's Anesthesia and Co-existing disease. 5th ed. Philadelphia: Churchill Livingstone; 2008:398-402.

4. Yildirim H, Adanir T, Atay A, Katircioglu K, Savaci S. The effects of sevoflurane, isoflurane, and desflurane on QT interval of the ECG. Eur J Anaesthesiol. 2004; 21:566-70.

5. Bajwa SJS, Sehgal V. Anesthetic management of primary hyperparathyroidism: A role rarely noticed and appreciated so far. Ind J Endocrinol Metabol. 2013;17:235-9.

6. Black MJ, Ruscher AE, Lederman J, Chen H. Local/cervical block anesthesia versus general anesthesia for minimally invasive parathyroidectomy: what are the advantages? Ann Surg Oncol. 2007;14:744-9. 